NBER WORKING PAPER SERIES

\title{
STABILITY FIRST: REFLECTIONS INSPIRED BY OTMAR ISSING'S SUCCESS AT THE ECB'S CHIEF ECONOMIST
}

\author{
Vitor Gaspar \\ Anil K. Kashyap \\ Working Paper 12277 \\ http://www.nber.org/papers/w12277
NATIONAL BUREAU OF ECONOMIC RESEARCH
1050 Massachusetts Avenue
Cambridge, MA 02138
May 2006

Prepared for the ECB Colloquium held in honor of Otmar Issing. We thank the organizers of the Conference, Klaus Masuch, Lucrezia Reichlin, Wolfgang Schill and Frank Smets for asking us to write the paper and for their suggestions and comments. We thank Vítor Constâncio, Lars Jonung and Jeremy Stein for helpful conversations. We gratefully acknowledge useful comments and suggestions by Marta Abreu, Olivier Blanchard, Alan Blinder, Steve Cecchetti, Silvia Luz, Huw Pill, David Vestin and Mike Woodford. We are particularly grateful to Rasmus Pilegard, Tatiana Tekušová, Robert Szemere, Daniel Ryden and Pedro Próspero Luís for providing us with data we used in section 1. The views expressed in the paper are our own, and are not necessarily shared by the institutions with which we are affiliated. All remaining errors are our own. The views expressed herein are those of the author(s) and do not necessarily reflect the views of the National Bureau of Economic Research.

(C2006 by Vitor Gaspar and Anil K. Kashyap. All rights reserved. Short sections of text, not to exceed two paragraphs, may be quoted without explicit permission provided that full credit, including $\odot$ notice, is given to the source. 
Stability First: Reflections Inspired by Otmar Issing's Success as the ECB's Chief Economist Vitor Gaspar and Anil K. Kashyap

NBER Working Paper No. 12277

May 2006

JEL No. E31, E52, E58, E44

\begin{abstract}
$\underline{\text { ABSTRACT }}$
In this paper, we review Otmar Issing's career as the ECB's inaugural chief economist and we document many notable successes. We try to infer some general principles that contributed to these successes and draw some lessons. In doing so, we review the evidence using Woodford's (2003) recent revival of the Wicksellian approach to monetary policy making. Suitably interpreted the baseline model can rationalize Issing's three guiding principles for successful policymaking. This baseline model, however, fails to account for the important role that monetary and financial analysis played in the conduct of policy during Issing's tenure. We propose an extension of the model to account for financial developments and show that this extended model substantially improves our understanding of ECB practice. We conclude by listing six open questions, relevant for the future of central banking in Europe that Issing may want to consider in case leisure allows.

Vitor Gaspar

Banco de Portugal

148, Rua do Comercio

1101 Lisbon Codex

PORTUGAL

vitor r gaspar@bportugal.pt

Anil Kashyap

Graduate School of Business

The University of Chicago

5807 S. Woodlawn Avenue

Chicago, IL 60637

and NBER

anil.kashyap@ chicagogsb.edu
\end{abstract}


"It is in the nature of beginning that something new is started which cannot be expected from what may have happened before. This character of startling unexpectedness is inherent in all beginnings."

Hannah Arendt, Human Condition, page 177-178.

"Excellence, then is a state concerned with choice (...) being determined by the right rule and in the way in which the man of practical wisdom would determine it."

Aristotle, Nicomachean Ethics, 1106b36-1107a2.

We review Otmar Issing's service as the inaugural Chief Economist of the European Central Bank (ECB). During his 8 years in the post he faced many unique challenges. Many of the hurdles associated with creating a new central bank and launching a new currency could have been anticipated, but some such as the terrorist attacks in September 2001 and the Asian Financial crisis in the Fall of 1998 (as the final preparations for the ECB were underway) could not have been foreseen. We study the choices that Issing and his colleagues made in confronting these challenges, the performance of monetary policy over the period and ask if there are any lessons that can be drawn from this episode.

Early in his tenure Issing revealed his thinking on many of these matters. Specifically in 1999 he wrote: ${ }^{1}$

"As a central banker directly involved in monetary policy making, I have been dealing with uncertainty and its consequences for a large part of my professional life.(...) But never have I felt the impact of uncertainty as acutely as in the weeks that preceded the introduction of the euro and the birth of the single monetary policy.(...) when the Governing Council made its final announcement on the monetary policy strategy and was getting ready for the Changeover Weekend, the uncertainty was at its peak. Nothing could be taken for granted, no matter how careful the preparatory work had been."

Perhaps because of this awareness Issing designed a monetary policy framework that accounted for the uncertainties confronting the newly formed central bank. In doing so, he faced at least six specific challenges. The first has to do with data uncertainty. Here we may distinguish two different aspects. The creation of the euro area, a new economic entity, introduced a discontinuity in existing statistical time series. Historical time series for the euro area exist only since 1999. In order to perform econometric analysis it is necessary to use synthetic aggregates, based on national data, before 1999. The other aspect to bear in mind relates to the fact that, at the start, the timeliness and scope of information was below the standard, normally available to the central bank of an industrialized country.

\footnotetext{
${ }^{1}$ Otmar Issing, Monetary Policy of the ECB in a World of Uncertainty, Address to the ECB Conference Monetary Policy Making under Uncertainty, December 1999.
} 
Secondly, the creation of the ECB and the start of the single monetary policy could be expected to induce a structural break a la Lucas (1976). Interestingly the available evidence suggests that, probably because of the gradual convergence process prior to monetary unification, no discontinuity took place.

Thirdly, the introduction of the euro is a catalyst for structural change leading to deeper trade and financial integration. Changing patterns of integration, in turn, affect the linkages across euro area economies. Already in 1999, Wim Duisenberg, the first President of the ECB, underlined the importance of obtaining better knowledge about the structure and functioning of the euro area economy and, in particular, of the transmission mechanism of monetary policy. For policymakers this meant that they needed to account for both parameter uncertainty and model uncertainty.

Fourth, the ECB as a new institution, had to start operating without the benefit from a track record. Blinder (1999), in his book, portrays central bankers as obsessed with credibility. There are excellent reasons for such obsession. When inflation expectations become unhinged, inflation dynamics become unstable with inflation literally feeding on itself. The experience of the Great Inflation testifies how economic performance is affected and how long it takes to re-establish price stability.

Fifth, as stressed above, the creation of a new central bank, responsible for the conduct of monetary policy in a new economic entity the euro area is an event of historical magnitude, in the context of European integration. It is a major defining moment of constitutional relevance. Nevertheless, many issues of governance, political legitimacy and political accountability remain open, potentially affecting the position of central bank in the political realm.

Finally, a source of immediate concern, in the early days of the ECB, related to some specific difficulties associated with the transition process. Obstfeld (1998) refers to both the fixing of the conversion rates of national currencies to euro and the start of operations of the European large value payment system (TARGET), an essential ingredient for a smooth transition to the new Eurosystem's operational framework for the implementation of monetary policy.

Against this backdrop, and the ECB's mandate to deliver price stability, over the medium term, we evaluate the policy strategy that the ECB adopted. We argue that it has worked surprisingly smoothly and surprisingly well. Issing is at the root of this outstanding performance. This explains the quote from Aristotle in epigraph to this paper. According to Aristotle, practical deliberation, meaning, for our purposes policy-making, can never be fully scientific. There must always be an element of art, associated with the ability to grasp the relevant particulars. Decisions are always made in concrete, individual, historical context. However, this is not the aspect we will want to highlight. Instead, we want to recall that also, according to Aristotle, the standard of excellence in decision-making is the man of practical wisdom. In other words, it is the successful policy-maker.

Thus, according with Aristotle's viewpoint, we ask, in this paper, whether the ECB's success under Issing happened as predicted by a variant of the New Keynesian model (clearly derived and systematically explored in Woodford 2003). We offer this model not because it necessarily characterizes Issing's views of the structure of the economy 
or the monetary transmission mechanism, but rather because it has become the workhorse model used in the academic literature studying monetary policy design.

We find that ECB practice and the predictions of benchmark model depart most sharply regarding the importance of the financial system in the conduct of monetary policy. Most renditions of the traditional model abstract from any structural representation of the monetary and financial system and of the role of the financial system in the transmission mechanism of monetary policy. We believe that this may prove a very important omission for our ability to understand the actual conduct of policy. In the spirit of Wicksell we distinguish between the policy rate and the loan rate (which is the relevant rate for determining spending decisions). We extend the standard model in a very simple way to take into account this additional complication. We argue that by doing so we can better understand actual ECB conduct.

The rest of the paper is organized as follows. In section 1 we present an overview of the single monetary policy after seven years. We stress the unique, historical changes, associated with the creation of the euro area and the starting up of the ECB. We go on to ask

Has the stability-oriented monetary policy strategy worked?

How did it work?

Given the perspective taken in the paper it is clear that the answer to the first question will be yes.

In section 2 we will discuss a model that includes some minimum conditions, which are necessary in order for monetary policy to be effective. The conditions we will be focusing on derive from the role of money as a unit of account. Specifically, we use a fundamental equation that appears in most models using a new Keynesian or New Neoclassical Synthesis approach to monetary policy making (these include Goodfriend and King, 1997, 2001, Clarida, Gali and Gertler, 1999, Svensson and Woodford, 2005 and Christiano, Eichenbaum and Evans, 2005). In this class of models the fundamental friction comes from imperfect price adjustment associated with the mechanism of nominal price setting by monopolistic competitive firms. We focus on optimal policy as implied by the Woodford (2003) variant of the model, and relate the model's policy prescriptions to those annunciated by Issing.

In section 3 we will look at the transmission mechanism of monetary policy through the financial system, in general, and the banking system, in particular. Woodford's model also spells the connection between policy rates and expenditure precisely. In his basic set-up, there is a direct link between the policy rate and expenditure. However, going back to Wicksell there have been debates as to how to model the relevance of the financial system in the transmission of monetary policy. Inspired by Wicksell we will minimally depart from the standard set-up and introduce a second interest rate that matters for spending. In deference to Wicksell will call this rate the "loan" rate. ${ }^{2}$ Such extension allows us to consider important issues such as liquidity, financial stability and asset prices and their relevance for the conduct of monetary policy.

\footnotetext{
${ }^{2}$ See Brainard (1964), Brunner and Meltzer (1972, 1993), Friedman (1970), Tobin (1969), Bernanke and Blinder (1988) and very recently Cecchetti and $\operatorname{Li}(2005)$ ).
} 
In section 4 we will conclude and list a number of open questions that men of practical wisdom (in particular Otmar Issing) may want to reflect upon.

1. Brief overview of the Single Monetary Policy 1999-2005.

The questions we will examine in this section are:

Has the stability-oriented monetary policy strategy worked?

How did it work?

The answer to the first question is clearly yes. The European Union Treaty and the statute of the ECB and the European System of Central Banks (EUT and the Statute) state that maintaining price stability is the primary goal of monetary policy. On October 13, 1998, the Governing Council adopted a precise, quantitative definition of price stability based on a specific statistical indicator: "Price stability shall be defined as year-on-year increase in the Harmonized Index of Consumer Prices (HICP), for the euro area of below 2 percent. (ECB (1998))." The ECB's aim was to maintain price stability over the medium term. On May 8, 2003, the Governing Council further clarified that it aimed at maintaining inflation below (but close to) 2 percent, over the medium term. ${ }^{3}$ Table 1 and Chart 1 show that ECB has essentially attained this goal: the average annual increase, in the HICP, during the first seven years of the single monetary policy has been very close, but not below 2 per cent.

The announcement of a precise, quantitative definition of price stability, based on a specific indicator fulfills three functions: by making the primary objective more visible and easier to understand it makes monetary policy more transparent and predictable. The definition also provides an objective yardstick against which the performance of the monetary authority may be measured. Thus, it helps accountability. Lastly, the definition, together with the medium term orientation, helps anchoring inflation expectations enhancing the credibility of policy.

One fundamental characteristic of the ECB's approach to maintaining price stability is its medium-term orientation (ECB (1999)). Apart from providing a long term anchor to expectations a medium-term orientation also allows, after a shock, for a gradual approach in returning to price stability. Such a gradual approach may be called for in order to avoid unnecessary volatility in economic activity and interest rates. An important qualification follows from the fact that the ECB has always emphasized that the relevant time horizon is not constant. It depends on the current state, the nature and characteristics of the shocks and on the functioning of the economy. Moreover, a medium term orientation also acknowledges the importance of long and variable lags of monetary transmission, avoiding the dangers of short-sighted activism. In other words the uncertainties associated with the timing and magnitude of monetary policy actions is too great to allow for fine-tuning of short term developments in the price level.

\footnotetext{
${ }^{3}$ See $\operatorname{ECB}(2003 \mathrm{a}, 2003 \mathrm{~b})$ and Issing et al (2003) for more details.
} 
The remark above that inflation was, in the period 1999-2005, close (but not below) 2 percent is an example of an ex post evaluation of the performance of policy. The small deviation is easily accounted for given the accumulation of a long list of miscellaneous shocks to the price level (e.g. oil prices and other commodity prices, food prices, administered prices and indirect taxes). Examining Chart 1 it becomes clear that the ECB has also been successful in keeping price stability, in the more imprecise sense of maintaining inflation low and stable. Moreover, given the medium term orientation the differences between the various indicators included in the Chart are immaterial.

Insert Chart 1 about here

Table 1: Price Stability and overall Macroeconomic Stability.

\begin{tabular}{|l|r|r|r|r|r|r|r|r|}
\hline & \multicolumn{4}{|c|}{ Euro Area } & \multicolumn{2}{c|}{ US } \\
\hline & $1990-1998$ & $1999-2005$ & $1990-1998$ & $1999-2005$ \\
\hline & Average & StDev & Average & StDev & Average & StDev & Average & StDev \\
\hline HICP/CPI 12th month \% change & 2,81 & 1,07 & 2,01 & 0,46 & 3,10 & 1,14 & 2,53 & 0,71 \\
\hline Real GDP quarterly \% change & 0,48 & 0,52 & 0,46 & 0,36 & 0,76 & 0,53 & 0,71 & 0,53 \\
\hline Real Consumption quarterly \% change & 0,48 & 0,58 & 0,43 & 0,40 & 0,78 & 0,51 & 0,87 & 0,41 \\
\hline Employment quarterly \% change & 0,12 & 0,34 & 0,28 & 0,24 & 0,32 & 0,35 & 0,26 & 0,44 \\
\hline Unemployment rate & 9,80 & 0,99 & 8,55 & 0,47 & 5,93 & 0,97 & 5,05 & 0,79 \\
\hline Long-term interest rates & 8,23 & 1,98 & 4,60 & 0,64 & 6,78 & 1,04 & 4,86 & 0,82 \\
\hline Short-term interest rates & 7,62 & 2,80 & 3,13 & 0,96 & 4,88 & 1,29 & 2,95 & 1,79 \\
\hline
\end{tabular}

Source: Masuch (2005)

As already noted the Governing Council definition of price stability is not only a benchmark for ex post accountability but also an anchor for inflation expectations. The latter aspect is closely linked to credibility. Thus, in the second place, we must examine the ECB's performance in terms of credibility. Chart 2 plots two such measures the five-year ahead inflation forecast, from the ECB's Survey of Professional Forecasters and the 10-year break-even inflation rate recovered from the 10-year index linked bond. ${ }^{4}$ From the Chart it is clear that expectations have been stable and consistently close to the ECB's definition of price stability (please notice the scale on the vertical axis). Castelnuovo and others (2003) and Gaspar (2003) have shown that there is a very low correlation between short run forecasts (or changes in short run forecasts), which are much more volatile, and long run forecasts (or changes thereof).

\section{Insert Chart 2 about here}

At the same time it is clear from Table 1 (which is taken from Masuch, 2005) that the stability of inflation and inflation expectations has coincided with low volatility of important real variables like GDP and employment. Low volatility compared with the recent past (but also longer time periods, see Masuch, 2005) and also with the US -

\footnotetext{
${ }^{4}$ Computed on the basis of bonds, issued by the French treasury, indexed to the euro area HICP, maturing in 2012. The break even inflation rate is computed by equating the yield to maturity on the real bond to the nominal bond with the same maturity.
} 
where volatility was also fallen recently. The drop in volatility is particularly marked for financial variables like long term interest rates.

It is worthwhile to pause to consider the facts. Clearly it is not possible to conclude from comparing volatilities that monetary policy has caused such improvement. ${ }^{5}$ However, in the literature following Rogoff's (1985) contribution, it was expected that delegation of monetary policy to an independent (conservative) central bank would lead to lower inflation on average and to higher volatility of output. Alesina and Summers (1993) looked at this proposition using a sample of OECD countries. They found that central bank independence was, as expected associated with lower average inflation, but also that the variance of growth or employment were not related to central bank independence. In such perspective the experience of the ECB adds to the evidence pointing to the compatibility between price stability and overall macroeconomic stability. We will comment on this further below.

How has it worked?

In the Eurosystem, as in all modern central banks, monetary policy operates first through a short tem interest rate. The central bank offers two standing facilities: a lending and a deposit facility. The two standing facilities define a corridor limiting the fluctuation in the overnight rate. Moreover, the ECB steers market interest rates though its regular main refinancing operations. If we look at Chart 3 the first few weeks of 1999 - the start of the single monetary policy - do not stand out. It shows that banks adapted quickly and easily to the new environment. The evidence suggests that the precautions taken by the Governing Council, on 22 December 1998, in particular the narrow corridor (of just 50 basis points) defined by the marginal lending facility and the deposit facility, effectively contained money market volatility. After a few teething problems in the first few days the situation rapidly stabilized so that already on 21 January 1999 the ECB was able to announce the normalization of the corridor width effective from the following day onwards. The start of the Eurosystem's operational framework and of the TARGET system occurred in a seamless way (calming the concerns referred to in the Introduction). ${ }^{6}$

\section{Insert Chart 3 about here}

To sum up: after seven years the balance of the single monetary policy is impressive:

- The transition to the single monetary policy has been seamless.

- Price stability over the medium term has been maintained.

- Inflation expectations have been low, stable and (by and large) compatible with the ECB's definition of price stability.

- Volatility of macroeconomic variables has declined.

- Volatility of long term bond yields has declined as well.

\footnotetext{
${ }^{5}$ However, see Cecchetti, Flores-Lagunes and Krause (2006) for some evidence that monetary policy might be responsible.

${ }^{6}$ See Gaspar, Perez-Quirós and Sicilia (2001) for more detailed documentation on the operational transition to the single monetary policy.
} 
In our view much of this success is attributable to the monetary policy strategy that Issing helped design. Issing (Issing et al, 2005, pp 75-76) summarizes the policy and strategy that emerged as follows:

"As in the Bundesbank's case, the ECB's approach involves both rule like features, consistent with the results of monetary theory, and an attention to central banking experience in the implementation phase. The key messages from monetary policy theory which emerge through the lens of my professional experience can be stated as follows:

- don't try tricks, don't try to be too clever;

- keep steady, keep committed to your mandate even in exceptional circumstances;

- say as much as you can of what you are going to do: announce a strategy;

- don't be dogmatic, but follow a policy which is always in line with your strategy."

He concludes by announcing three principles for successful conduct of monetary policy.

1) Institutions matter. Central bank independence and a mandate for price stability are crucial pre-requisites for successful central banking: "Sound institutional arrangements play a central role. Historical evidence and theory agree in pointing out that central bank independence and a clear mandate for price stability are the basic elements of a sound institutional set-up."

2) Credibility is paramount: "They provide the premises to establish credibility, to anchor inflationary expectations and ultimately deliver price stability and foster a stable macroeconomic environment."

3) Temptation must be resisted. Moral responsibility and fortitude are fundamental in the face of economic complexity and change: "We must never forget this message, nor ever take credibility for granted, even at times when price stability is established and there seem to be minor challenges ahead. Credibility is hard to gain, but it is easily lost. To be maintained, it requires continuous vigilance. If lost, it can be regained only at high costs to society."

The ECB's monetary policy embodies these three principles. The ECB's mandate and independence are enshrined in the European Union Treaty and in its Statute. Thus, they have a constitutional character in Europe. Moreover, the strategy is medium term oriented, forward-looking and based on a full information approach. Its assessment of the current economic situation and risks to price stability is based on two complementary viewpoints: economic analysis and monetary analysis. Furthermore, the communication strategy of the ECB is organized around explaining interest rate decisions in terms of how they relate to the price stability mandate. ${ }^{7}$

\footnotetext{
${ }^{7}$ An important part of the communication strategy has also to provide regular updates on the ECB's experience and what the experience implied for the monetary policy strategy. See Issing (1999b, 2000, 2001c, and 2005).
} 
In this section we will not comment further on specific decisions and their circumstances. We will look at some examples in the following sections.

However, before moving on, it is important to note that during this period many important events took place at the European level. A partial list includes the disappointing pace of structural reforms in many Member States and in the EU as a whole, as is clear from the European Commission own review of the Lisbon strategy, the debate over budgetary discipline and the Stability and Growth Pact (culminating with the ruling of the European Court of Justice and the revision of some secondary legislation), the enlargement of the European Union to include ten new Member States and the rejection of the European Constitution in referenda by French and Dutch voters.

Issing (1995) wrote:

"In view of European integration, the role and responsibilities of the central bank are assuming international and supranational dimensions to an unprecedented extent. Since nothing less than the future constitution of the Community is at stake in this integration process, the position of the future European central bank within the overall pattern of the "political union" is not the least of issues that have to be considered and decided."

And in (2001a) he wrote a paper where he started, as an economist by posing the question: Can One Size Fit All? And ended with his passionate answer that as an European citizen "At this juncture monetary union simply cannot fail. It must succeed: One size must fit all."

The first question we address to Otmar Issing is:

Monetary union is a major institutional change that will necessarily lead to important behavioral changes, which cannot be accurately foreseen. At the same time, proper functioning of the monetary union also calls for institutions to change, for structural reform.

Given the fact the monetary, economic and political trends are co-determined and coevolutionary what is the ground for optimism about the future of the European Union? How will political forces affect the operation of the European Central Bank and the Eurosystem? 
2. Economic Analysis: Maintaining Price Stability and Anchoring Inflation Expectations.

"If it were in our power to regulate completely the price system of the future, the ideal position ... would undoubtedly be one in which, without interfering with the inevitable variations in the relative prices of commodities, the general level of prices ... would be perfectly invariant and stable. And why should not such regulation lie within the scope of practical politics? ... Absolute prices ... are a matter in the last analysis of pure convention, depending on the choice of a standard of price which lies within our power to make."

Knut Wicksell, Interest and Prices, page $4 .^{8}$

In this section, we follow the approach proposed by Aristotle and ask whether the successes that have just been documented accord with the predictions of the kind of model that has become the standard in the academic literature that studies optimal monetary policy decision-making. We focus on specifically on the fundamental equation that appears in most models using a new Keynesian or New Neoclassical Synthesis approach to monetary policy making (these include, among others, Goodfriend and King, 1997, 2001, Walsh, 1998, Goodfriend, 2002 and Svensson and Woodford, 2005). Our analysis draws most heavily on the variant of this model studied by Clarida, Gali and Gertler (1999) and by Woodford (2003).

This model rests on several critical assumptions. First, it presumes that the goods market is populated with a set of monopolistically competitive firms as in Dixit and Stiglitz (1977). Second, this imperfect competition means that firms must set prices. As in Calvo (1983), firms commit to a fixed nominal price in advance of knowing the demand for that period. At the end of each period a fraction of the firms are allowed to adjust their price freely, while the remaining firms increase theirs' based on the inflation rate observed in the period. This so-called partial indexation assumption is made so that the model's predicted persistence in inflation will match that found in the data. We also will explore the implications of dropping the indexation. Third, firms produce using labor under a marginal diminishing returns technology. Fourth, output is demand determined at the set price.

Finally, the model allows for shocks that create a tension between price stability and output gap stabilization. For example, in the case of a positive "cost-push" shock inflation rises and output falls relative to its natural level.

Inflation in this framework is inefficient because firms have promised to meet demand at their fixed nominal price. Consequently aggregate inflation moves real, relative prices (which is inefficient). We consider model's presumption of nominal price rigidity as appropriate since absent some sort of price stickiness monetary policy will be neutral; if prices can all adjust proportionally following a change in the quantity of

\footnotetext{
${ }^{8}$ Quoted in Michael Woodford's Interest and Prices, page 1.
} 
money then no real quantities (including most importantly the real interest rate) will be affected by monetary policy. ${ }^{9}$

One of Issing's contributions to this debate was to promote basic research on these issues and in this case the Eurosystem Inflation Persistence Network produced a wealth of information on price setting and inflation dynamics. A very short summary of findings from micro data sets is that prices do change infrequently (only about 15 percent of consumer prices change each month). Thus, price stickiness is clearly documented. When prices do change, they can either increase or decrease. In euro area data, 60 percent of the prices changing are increases, while 40 percent are declines. Price changes are sizeable (on average 8 per cent for price increases and 10 per cent for price decreases). There is no evidence of mechanical indexation to past inflation, undermining the micro-foundations, for the inclusion of lagged inflation, in the New Keynesian Phillips curve. Price reviews are more frequent than price changes, which calls into question the rational inattention version of the sticky information story (for additional elaboration and complete references see Angeloni et al, 2004, Issing (2004), Fabiani et al., 2005 and Alvarez et al., 2005). In any case, for the remainder of this paper we will follow the dominant trend in the literature to stick to the Calvo price-setting assumption.

Woodford (2003) shows that under rational expectations, these standard assumptions lead to a Phillips curve of the form

$$
\pi_{t}-\gamma \pi_{t-1}=\beta\left(\mathrm{E}_{t} \pi_{t+1}-\gamma \pi_{t}\right)+\kappa x_{t}+u_{t},
$$

where $\pi$ is inflation, $x$ is the output gap, $\beta$ is the discount rate, $\kappa$ is a convolution of the structural parameters, $\gamma$ is the degree of indexation of prices, not optimally set each period, and $u$ is a cost-push shock (assumed i.i.d.). Thus, in equation (1) inflation is determined by lagged inflation, inflation expectations, the output gap and the shock. In this section, we will simply assume that the central bank directly controls the output gap, thereby abstracting from the complexities of the monetary transmission mechanism. ${ }^{10}$ The assumption does not affect the main results we will present. We postpone the discussion of the importance of the monetary transmission mechanism to section 3 .

Furthermore, up to a second order approximation, the (negative of the) period social welfare function (as also shown in Woodford, 2003) takes the form

$$
L_{t}=\left(\pi_{t}-\gamma \pi_{t-1}\right)^{2}+\lambda x_{t}^{2}
$$

where $\lambda$ is another function of the underlying structural parameters.

The problem of minimizing the loss function in equation (2) subject to the linear constraint (1), given by the New Keynesian Phillips curve resembles the classic linear quadratic framework explored in the 1950s by Simon (1956) and Theil $(1954,1957)$. Simon and Theil extended the deterministic framework of Tinbergen (1952) to a

\footnotetext{
${ }^{9}$ We are less convinced that the Calvo formulation of the rigidity is necessarily appropriate and are intrigued by the recent papers such as Klenow and Kyvstov (2005), Golosov and Lucas (2005) and Gertler and Leahy (2006) that explore competing formulations.

${ }^{10}$ Clarida, Gali and Gertler (1999) explain the approach we follow, by appealing to a division of the optimal policy problem in two stages. In the first stage, the one we will focus on, the optimal path of inflation and the output gap are determined. In the second stage, the policy rate path, compatible with the optimal solution, determined in stage one, is worked out using a forward-looking IS curve.
} 
stochastic set-up and showed that, in the linear-quadratic framework, both certainty equivalence and the separation of estimation and control held true. The main difference of our problem relative to the classical policy instrument choice framework is that expectations about the future are endogenous and influence the current state of the economy. Recently, Svensson and Woodford (2003) have identified conditions for these results to hold in models with forward-looking behavior.

The first order conditions for the central banker's problem may be shown to imply:

$$
x_{t}=-\frac{\kappa}{\kappa^{2}+\lambda} u_{t}
$$

Under the optimal discretionary policy, the output gap only responds to the current cost-push shock. In particular, following a positive cost-push shock to inflation, monetary policy is tightened and the output gap falls. The strength of the response depends on the slope of the New Keynesian Phillips curve, $\kappa$, and the weight on output gap stabilization in the loss function, $\lambda$. The reaction function in (3) contrasts with the one derived in Clarida, Gali and Gertler (1999). They assume that the loss function is quadratic in inflation (instead of the quasi-difference of inflation) and they find that, in such a case, the output gap is also a function of lagged inflation.

The corresponding equation for inflation as a function of the shock is:

$$
\pi_{t}=\gamma \pi_{t-1}+\frac{\lambda}{\kappa^{2}+\lambda} u_{t}
$$

Equation (4) makes it clear that under partial indexation inflation will respond gradually and persistently to a temporary cost push shock. Inflation persistence contrasts here with a non-persistent response of the output gap to cost-push shocks (assumed to be i.i.d.).

Expressing inflation directly as a function of the output gap:

$$
\pi_{t}-\gamma \pi_{t-1}=-\frac{\lambda}{\kappa} x_{t} \quad \text { or } \quad x_{t}=-\frac{\kappa}{\lambda}\left(\pi_{t}-\gamma \pi_{t-1}\right) .
$$

The solution under commitment is considerably different. Specifically, the expression relating the output gap and inflation becomes ${ }^{11}$ :

$$
x_{t}-x_{t-1}=-\frac{\kappa}{\lambda}\left(\pi_{t}-\gamma \pi_{t-1}\right)
$$

What general principles for the conduct of monetary can we extract from this set-up? What questions remain for a wise policy-maker?

First, all models incorporating the type of nominal rigidity that we have discussed imply a strong case for price stability. The idea, which does not seem to depend on the details of the modeling strategy, is that the allocative inefficiency, associated with

\footnotetext{
${ }^{11}$ The first order condition relative to the first period would be different. We disregard such peculiarity assuming that the optimization was performed a long time in the past. This is the idea of Woodford's timeless perspective.
} 
relative price dispersion will, in general, be eliminated by the stability of the aggregate price level (assuming $\gamma<1$ ). The way to achieve such an outcome is to follow a monetary policy regime where firms, when setting prices, will have no desire to change them. Such decisions, in turn, will validate the firms' initial expectations. In the absence of cost-push shocks the intuition behind this principle is clear. As Goodfriend and King $(1997,2001)$ stress nominal price stickiness is the only distortion preventing the identity between the rational expectations equilibrium and the first best allocation of resources. Thus, optimal monetary policy aims at reproducing the allocation of resources which would occur under flexible price equilibrium. Thus, the model clearly accords with Issing's first principle that emphasizes the primacy of a price-stability mandate and the wisdom of delegating such mandate to an independent central bank.

Second, it is apparent directly from equation (1) that policy credibility will also be important. In particular, given a positive cost push shock, the central bank is faced with a dilemma because the output gap will drop and inflation will rise. However, the tension depends importantly on what happens to expected inflation. If the public believes that the expected inflation will be lower following the temporary increase in inflation, the policymaker's problem is made less acute. Conversely, if the public foresees higher expected inflation it magnifies the shock making the policy dilemma worse. This observation rationalizes Issing's second principle that stresses the importance of credibility.

Issing's third principle focuses on the risks associated with caving in to the temptation to accommodate a shock and associated problems once inflation expectations become unhinged. The preceding discussion suggests that this is clearly possible. The importance of this consideration appears to center on the nature of the shocks that the policymaker must confront. The discussion in Clarida, Gali and Gertler (1999) is particularly illuminating on this point. They show that optimal policy calls for offsetting demand shocks and for accommodating shocks to potential output. In all such circumstances stabilizing prices ensures stability of the output gap (or alternatively the mark up). In such circumstances, Goodfriend and King (2001), explain that policy aiming at price stability is neutral policy precisely because it maintains output close to its potential. ${ }^{12}$ In all such circumstances there are no tradeoffs. So in these specifications only cost-push shocks create a dilemma for the central bank. Offsetting all other shocks is optimal so that only an incompetent central bank would fail to do so.

So what exactly are these cost push shocks? Woodford (2003) shows that, in the context of the current class of models, it is possible to ground cost-push disturbances

\footnotetext{
12 The model of Goodfriend and King is within the tradition of optimal taxation in general equilibrium, in the spirit of Ramsey (1927) and Lucas and Stokey (1983). The basic intuition follows from looking at the wedge between price and the marginal cost - the mark-up - as analogous to a tax rate. Constant mark-ups are optimal (or approximately optimal) in a way which is analogous to tax smoothing over the business cycle or uniform taxation in the optimal taxation literature. As in the optimal taxation literature there may be departures from optimality of constant mark-ups and price stability but they argue departures are likely to be minor and temporary. In their setting preserving price stability keeps output at potential.
} 
on time-varying tax wedges or mark-ups. ${ }^{13}$ Alternatively, Benigno and Woodford (2004) show that in an extended model with other distortions, output will normally be below its efficient level so that other factors, such as exogenous government spending shocks also change the gap between the flexible price level of output and the efficient level of output varies over time. Thus, these disturbances introduce a trade-off between inflation volatility and output gap volatility.

Finally, in a recent paper Blanchard and Gali (2005) argue that the introduction of real frictions, in the model, creates an environment where the gap between the natural level of output and the efficient level of output fluctuates endogenously in response to economic shocks. Blanchard and Gali argue that real wage rigidity is more than an example of a real friction. It is their belief that real wage rigidities rank high in their ability to contribute to the empirical explanation of the business cycle. The model is also able to account for some empirical facts about inflation, namely its strong dependence on lagged inflation.

Taken together it seems that either using the baseline model sketched above, or more complicated variants involving more frictions, there will be a wide range of shocks that may create a temptation for the central bank. The possibility of yielding to temptation directly threatens credibility. As equation (3) shows optimal discretionary policy involves just a linear response to the cost-push shock. This implies that the output gap is not persistent (under the assumption of i.i.d. shocks) and inflation is persistent. Such policy is not globally optimal. Indeed, as Woodford (2003) shows, commitment to a history-dependent policy allows for the simultaneous reduction in the volatility of inflation and of the output gap. The ability to commit - that is credibility - is associated with welfare gains.

What explains this result? The key aspect is forward-looking behavior on the part of price setters. As Clarida, Gali and Gertler (1999) and Woodford (2003) show, a central bank will want to commit to pursue a policy of sustaining its response to costpush shocks so that the policy persists well after the shock has vanished from the economy. Specifically, a positive cost-push shock should be followed by a persistently negative output gap (and vice-versa). Such response is optimal because it generates expectations of a reduction in the price level that reduce the immediate impact of the shock, spreading it over time. With optimal policy, under commitment, inflation expectations operate as automatic stabilizers in the face of cost-push shocks. This stabilizing effect explains why it is possible to improve the inflation volatility, output gap volatility trade-off and why caving in to the temptation to combat these shocks would be misguided. Thus, it seems that simple extensions of the benchmark model account well for Issing's three key principles.

We are not sure Issing would agree. In Issing et al (2005), Issing recommends "skepticism in the application of theoretical results on how to optimally balance short term trade-offs and the belief that, once the benefits of medium and long-run price stability have been attained, the additional gains produced by such "optimized" policies are "small", and often model-dependent." Our second question to Otmar Issing, is thus: as a practical matter what are the most likely threats to the credibility

\footnotetext{
${ }^{13}$ The approach in Woodford (2003) is very common in the literature. See, for example, Clarida, Gali and Gertler (2001), Smets and Wouters (2003) and Steinsson (2003).
} 
of the European Central Bank? Which temptations are hardest to resist, what mistakes easiest to make? How important is communication with the European people as prevention against such possibilities?

We close this section by noting one further implication of the role of expectations as potential automatic stabilizers. Clarida, Gali and Gertler (1999) and Woodford (2003), show that the price level is stationary for the case of optimal policy under commitment (taking the timeless perspective). Under commitment and without partial indexation the policy rule may be written simply as:

(7) $x_{t}=-\frac{\kappa}{\lambda} \cdot\left(p_{t}-p^{*}\right)$

Woodford (2003) shows that the price level is stationary even allowing for partial indexation (provided $\gamma<1$ ). In addition, Vestin (2006) shows that, for the case $\gamma=0$, it is possible to implement fully optimal policy through the delegation of a target for the path of the price level to the central bank. Clearly, in such a case, it is possible to improve on the discretionary inflation targeting case by entrusting a price path target to the central bank. Inflation volatility and output gap volatility can be reduced. Therefore, even in the case of a society that cares only about inflation and output gap stability, it might still be beneficial to entrust the central bank with a price level mandate. This is just one example of a modified loss function (as in Rogoff (1985) or Walsh (1995)).

The main alternative to sticky price is sticky information models, which, recently have been formulated on the basis of behavioral models. ${ }^{14}$ Interestingly the conclusions for policy are very similar to those summarized above. Ball, Mankiw and Reis (2003) show that optimal policy stabilizes the path for the price level in response to productivity and demand shocks. In case shocks to mark-up levels are added the optimal response becomes, as before, flexible targeting of the price level.

Before putting forward our third question to Issing it is necessary to take a step back and look at the role of money as a unit of account. Robert Shiller (1997) illustrates the important role of money as a unit of account in long-dated financial contracts. The absence of indexation clauses in most contracts is a puzzle given the magnitude of long term inflation risk in historical time series. The relevance is clear when thinking about buying real estate or planning for retirement. From such a viewpoint price level stability appears important in its own right. These important aspects of the role of money as a unit of account are not present in the theoretical frameworks we have presented in this Section. Moreover, as Coulombe (1997) was among the first to point out, price level targets help to alleviate the zero lower bound on interest rates constraint on monetary policy. The reason is that they are consistent with increasing inflation expectations in the face of deflation shocks. ${ }^{15}$ Lastly, it seems from the implications of the current vintage of sticky prices and sticky information models, that we have considered here, that a focus on price level stability would lead to even better outcomes in terms of inflation and output gap variability. In such context, focusing on

\footnotetext{
${ }^{14}$ See Blanchard (1990).

${ }^{15}$ Gaspar and Smets (2000) present some simulations illustrating the relevance of this argument.
} 
price level stability can be interpreted as a commitment device. ${ }^{16}$ In "Why Price Stability?"17 Issing states "that the question of whether to focus on the price level or the inflation rate remains an open issue".

After more than five years and given the results reviewed above, our third question to Otmar Issing is ${ }^{18}$ : Is time now ripe to consider again the costs and benefits of stabilizing the path for the level of prices (rather than the inflation rate)? Why not price level stability?

\section{Monetary and Financial Analysis}

While the baseline model succeeds, albeit under duress, in delivering Issing's three principles, we argue in the remainder of the paper that it ignores monetary and financial analysis that plays an important role in ECB's decision-making. The easiest way to see the omission is to study Chart 4, which shows the ECB's description of the monetary transmission mechanism. ${ }^{19}$ The logic of the New Keynesian model can be traced through the left hand side of the Chart, which shows the link between the official interest rate, expectations and prices. The Chart, however, also shows that policy is believed to operate by affecting bank and market rates, which independently are thought to influence prices.

Modeling the transmission mechanism using a single interest rate has a long tradition in macroeconomics (e.g. in the IS/LM model). Bernanke and Blinder (1988) argued that the IS/LM model could be usefully extended by allowing for a second interest rate. The argument that follows makes the same point in the context of the New Keynesian model. More specifically, we argue that a second interest rate is also necessary to capture Wicksell's view of the economy. We start the discussion by reviewing a few key episodes that are odds with the baseline model and then discuss extensions necessary to understand the observed ECB practice.

We find it useful to consider three episodes where monetary and financial conditions drove monetary policy decisions and actions. To be concrete, we briefly review the ECB's actions related to the asset market turbulence in the Fall of 1998 and September 2001, as well as the words used to discuss possible asset market bubbles.

In the second half of 1998, just at the ECB was preparing for the launch of the common monetary policy, the international financial system was hit with a series of shocks. First, on August $17^{\text {th }}$ the Russian Government devalued the ruble, defaulted on its domestic debt and declared a moratorium on its payment to foreign creditors (see Chiodo and Owyang (2002) for a summary of the events).

The losses on the bonds destroyed the capital of the Long-Term Capital Management (LTCM) hedge fund. LTCM was a hugely levered entity and it began looking for

\footnotetext{
${ }^{16}$ See Vestin (2006).

${ }^{17}$ Issing (2001b)

${ }^{18}$ See Dugay (1994) for an early survey of the issues raised by price level targeting as an alternative to inflation targeting.

${ }^{19}$ See ECB, 2004, Chart 3.1. The ECB's account of the monetary transmission mechanism and its empirical features in the euro area are presented in section 3.2., pages 45-49.
} 
additional financing. By mid-September it became clear that LTCM was at risk for failing. Alan Greenspan, Chairman of the Federal Reserve, described the situation as follows: ${ }^{20}$

"It was the judgment of officials at the Federal Reserve Bank of New York, who were monitoring the situation on an ongoing basis, that the act of unwinding LTCM's portfolio in a forced liquidation would not only have a significant distorting impact on market prices but also in the process could produce large losses, or worse, for a number of creditors and counterparties, and for other market participants who were not directly involved with LTCM. ...

Financial market participants were already unsettled by recent global events. Had the failure of LTCM triggered the seizing up of markets, substantial damage could have been inflicted on many market participants, including some not directly involved with the firm, and could have potentially impaired the economies of many nations, including our own."

On this logic the Federal Reserve Bank of New York helped organize a rescue of LTCM. Nonetheless, spreads on corporate securities relative to government securities widened and many firms were unable to roll-over their commercial paper when it came due.

At the September $29^{\text {th }}$ FOMC meeting, the Federal Reserve cut the Federal Funds rate 25 basis points, from to 5.5 to 5.25. Donald Kohn (who was then a staff member) summarized the case for the cut as follows: ${ }^{21}$

"The case for easing does not rest on incoming data about the economy. As many of you have noted, the information that has come available since your last meeting indicates that the economy continues to expand at a pace around the growth rate of potential. That has kept the unemployment rate flat at a very low level and inflation has edged higher on a twelve month basis, at least as measured by the core CPI. Thus, a standard, backward-looking Taylor rule that called for a 5.5 percent funds rate in August would continue to do so today.

Rather, the case for easing relies on projections that have been marked down by developments overseas and in U.S. financial markets."

The Federal Reserve went on to cut interest rates two more times. In each case the FOMC pointed to conditions in financial markets (and not any direct evidence of weakness in spending) as the rationale for the moves.

The ECB's Governing Council also decided in November that a coordinated interest rate cut by the National Central Banks was in order. Thus, on December 31998 , there was a concerted reduction of official interest rates to 3 per cent. The move represented the final convergence of interest rates in preparation to the start of the single monetary policy. Remarkably, the average three month interbank rate declined, in the countries

\footnotetext{
${ }^{20}$ Testimony of Chairman Alan Greenspan, "Private-sector refinancing of the large hedge fund, LongTerm Capital Management” Before the Committee on Banking and Financial Services, U.S. House of Representatives October 1, 1998

${ }^{21}$ FOMC transcripts for the September 29, 1998 meeting, page 77.
} 
participating in the euro area, by about 70 basis points between August 1998 and the end of the year. Half of the adjustment took place following the decision of 3 December. Issing et al. (2001) explain the rationale for these moves on two grounds: First, weakness as recorded by leading indicators. Second, turmoil in international markets and negative wealth effects associated with stock market losses. These together with low inflation and inflation prospects implied that risks to price stability were moving to the downside.

The decisions taken by the ECB in the wake of the terrorist attacks against the United States on September 11, 2001 provide unambiguous evidence that the ECB acts as if shocks to the financial system can be important for monetary policy. In this case the ECB announced on that day that "the Eurosystem stands ready to support the normal functioning of markets. In particular, the Eurosystem will provide liquidity to the markets, if need be." It re-iterated this pledge the next day and conducted a "liquidity providing fine-tuning operation." On September 13, it reconfirmed the commitment to support the functioning of markets and repeated the liquidity providing fine-tuning operation. It also announced that it had opened a $\$ 50$ billion swap line with the Federal Reserve to "facilitate the functioning of financial markets and provide liquidity in dollars." On September 17, the bank cut the policy rate by 50 basis points. Thus, this is a case where the ECB perceived the disorder in financial markets to be critically important and was willing to act promptly to restore order. In any case it is important to point out that the decision was made easier because, at the same time, economic prospects for the euro area were also weakening.

Finally, throughout Issing's tenure at the ECB, one of the most hotly debated issues for both policymakers and academics has been the linkages between asset prices and monetary policy. There seems to be little dispute that a sharp decline in asset prices can be disruptive. For instance, there is broad consensus that the decade-long slump in Japan was triggered by a collapse in asset prices and then prolonged by spillover effects of the collapse into the banking system (IMF (2002)). There is also broad agreement that failure to deal decisively with financial system weakness was a major policy mistake (Bernanke (2000), Kohn (2006)). But, the question of what do when faced with a large increase in either equity prices or house prices remains contentious. $^{22}$

Issing (2003a) offers a nuanced view on how to deal with this. On the one hand he notes, "it is worth stressing that according to the previous arguments considering financial imbalances - from time to time - may lead to a different monetary policy stance than fixed-horizon inflation targeting, despite the fact that the only objective of the central bank is price stability (defined over the appropriate medium term horizon)." Yet on the other hand, if one does not adhere rigidly to the fixed-horizon then provided that "the central bank employs a medium term horizon for the definition of price stability and implies a strategy encompassing a stability-oriented, forwardlooking approach, financial imbalances will implicitly obtain the attention they deserve."

\footnotetext{
22 Issing's view on this (Issing (20003b) and Issing (2002)), which we agree with, is that pre-emptive policy moves based purely elevated asset values would be dangerous.
} 
Our fourth question to Issing is thus: some proponents of inflation targeting recommend focusing on an inflation forecast at a fixed time-horizon (say two years). Many times you have suggested that a flexible time frame, and sometimes a long time frame, maybe be necessary to cope with some shocks and risks. What are the most important considerations determining the length of the relevant time horizon? How can such considerations be most effectively communicated? Does the unwillingness to commit to a fixed time horizon create temptation that can undermine credibility?

Can the baseline new Keynesian model account for the right-hand side of Chart 4 ?

Up to this point we intentionally abstracted from the mechanism by which monetary policy affects the output gap. To determine whether we can reconcile the baseline model with the aforementioned concerns regarding the financial system we must explore these connections more thoroughly. In Woodford (2003, chapter 4) this connection is precisely derived. In particular, he shows that

(8) $x_{t}=\eta E_{t} x_{t+1}+\alpha\left(\rho_{t}-E_{t} \pi_{t+1}\right)+v_{t}$

where $\rho$ is the interest rate that is relevant for spending decisions and $\mathrm{v}$ is the aggregate demand shock.

One of the points of Woodford (2003) is that equation (8) is consistent with Wicksell's view of the economy. We agree with this, although Wicksell himself presumed that a "loan" rate was the relevant one for spending and so in deference to Wicksell we will refer to $\rho$ as a loan rate. As we explain below, $\rho$ could also be interpreted as the required return on equity or the corporate bond rate.

In contrast to the Wicksellian approach, the convention in the recent literature is to equate $\rho$ with the policy rate. We believe the distinction between treating $\rho$ as being perfectly and imperfectly linked to the policy rate is critical and that an extended model that presumes an imperfect connection generates several interesting insights.

One reason for considering an imperfect connection is that no users of this model believe that the short-term interest rate is the critical interest rate for spending. Instead one presumably equates $\rho$ with the policy rate because the appropriate longer term interest rate that belongs in (8) is itself a stable function of the policy rate; the expectations hypothesis of term-structure determination might justify this simplification if there were no time-variation in any term-premia. Cochrane and Piazzesi (2005), and many others document the considerable time-variation in termpremia. More importantly, the Fall 1998 and September 2001 episodes specifically suggest that policymakers are sometimes quite concerned about such variation. Indeed, Chart 4 shows that the ECB believes that it is crucial to monitor developments regarding the connections between the policy rate and market rates (and asset prices). ${ }^{23}$

${ }^{23}$ See ECB (2004) pages 44-49. 
Accordingly, in the remainder of the paper we explore the consequences of introducing a distinction between the policy rate and the loan rate. ${ }^{24}$ Specifically, we assume

$$
\rho_{t}=\varsigma_{t} x_{t}+\delta_{t}\left(i_{t}, \varepsilon_{t}\right) i_{t}+z_{t}
$$

where $\mathrm{i}$ denotes the policy rate and $\varepsilon$ a stochastic disturbance affecting the monetary transmission mechanism.

This formulation is admittedly ad-hoc and we make no attempt to provide micro foundations that deliver this precise equation. Instead, we view it as a relatively general specification that allows us to nest various hypotheses that have been put forward about the workings of financial markets. For instance, one way to think of (9) is as of a description of the equilibrium in loan market. Naturally, loan rates would rise when output is abnormally high - more generally we allow $\rho$ to depend on $\mathrm{x}$ to capture the effects of the demand for credit on the price of credit. Likewise, when the policy rate increases, loan rates tend to rise; in general arbitrage considerations would require expected rates of returns on other securities to rise when the rate of return on the safe asset increases.

We allow for time variation in $\delta$, the function governing the link between the policy rate and the loan rate, because of the evolving nature of intermediation (that we discuss further below). Under this interpretation, $\varepsilon$ would be a vector of factors that also affect the loan rate, such as the amount of capital in the banking system or the net-worth of borrowers. Finally, we allow for a disturbance $\mathrm{z}$ in the loan market that we also discuss shortly.

Substituting this back into the output gap equation yields the following:

$$
\left(1-\alpha \varsigma_{t}\right) x_{t}=\eta E_{t} x_{t+1}+\alpha\left(\delta_{t}\left(\mathrm{i}_{\mathrm{t}}, \varepsilon_{t}\right) \mathrm{i}_{\mathrm{t}}+z_{t}-E_{t} \pi_{t+1}\right)+v_{t}
$$

The usual special case considered by Woodford and most others in the literature presumes that $\delta$ and $\varsigma$ are known multipliers and $\mathrm{z}$ is zero. We see three reasons for generalizing in this way. First, we believe it allows us to formalize the concerns raised by Wicksell and others. Using Wicksell's framework it is natural to think about two wedges: first the wedge between the loan rate and the Wicksellian natural rate (the difference putting the "cumulative process" in motion) and second, the wedge between the loan rate and the policy rate. Second, it provides a convenient way to formalize a great deal of empirical evidence, including the large project on the monetary transmission that Issing initiated. Finally, it helps explain some aspects of the monetary policy strategy that has been practiced by the ECB. From this viewpoint,

\footnotetext{
${ }^{24}$ The alternative approach would be allow financial factors to matter, but to assume that this reflects un-modeled factors that affect desired spending; this amounts to assuming in (8) that $v$ and not $\rho$ is the relevant channel through which financial factors matter. It is possible that some cases, such as a decline in asset prices that reduce wealth, might naturally correspond to this interpretation. But, in other cases this assignment is less clear. For instance, the widening spreads on corporate bonds and commercial paper in the Fall of 1998 most naturally would be interpreted as raising the cost of capital for firms. Depending on whether there is any credit-rationing this type of shock might or might not belong in the residual in (8). Undoubtedly, the change in the spreads should appear in $\rho$.
} 
the loan rate is a summary of all the variables determining the financing conditions in the economy (as in ECB (2004)).

Taking (10) together with the Phillip's curve and a monetary policy rule allows us derive several propositions about the role of monetary and financial analysis in the conduct of monetary policy.

First, in the usual special case considered in the literature, the fact that spending depends on a loan rate and only indirectly on the policy rate would be inconsequential for the monetary authority. The policymakers would have to recognize that the coefficients on output and the policy rate in the aggregate demand equations are reduced form coefficients, but they would be stable reduced form coefficients.

Second, if $z_{t}$ is random and $\alpha$ is known certainty equivalence results apply. So this particular type of the uncertainty would have little practical impact on the central bank's conduct.

Alternatively, if relevant parameters are both unknown and time-varying then the central bank's job becomes much harder. The literature does not seem to provide any general insights. In cases where uncertainty is primarily about the static effect of the policy instrument on spending, then the problem looks much like the one studied by Brainard (1967) and the associated reasoning suggests that the policy-maker will behave cautiously (meaning he should move less than implied by certainty equivalence). On the other hand, if the uncertainty relates to the dynamic effects of policy, and the dynamics of the system threaten to become unhinged, then the central bank should be extra aggressive in responding to shocks, thereby stabilizing inflation.

As signaled by the quote from Issing at the start of this paper, he struggled with how to handle uncertainty throughout his career as a central banker. One further indication of the importance he placed on this problem is that he sponsored two major international conferences (in 1999 and 2004) on this theme of how to operate given uncertainty and imperfect knowledge.

He also supported a cooperative venture between the ECB and the National Central Banks of the Eurosystem to study the monetary transmission from a variety of angles. The Monetary Transmission Network (MTN) research offers the most complete assessment to date of how monetary policy appears to operate in the euro area.

It is particularly relevant, in the context of Chart 4, that much of the MTN research was aimed at studying the importance of shifts in bank loan supply in the transmission of monetary policy. Operationally this amounted to comparing changes in loan volumes for different types of banks (small versus large, liquid versus illiquid, members of groups versus independent, etc) following changes in policy rates. In terms of (9) these different bank characteristics would be candidates for $\varepsilon$. There was no single contrast the revealed systematic differences in all countries, although in nearly all cases it appears that banks with fewer liquid assets on their balance sheets seem to cut lending relatively more when policy rates rise. Thus, at an aggregate level the amount (and distribution of) liquidity in the banking system is one candidate proxy for $\varepsilon$ that deserves more scrutiny. Interestingly, neither the level of bank 
capital, nor the size of a bank seemed to be closely related to the degree to which bank lending changes.

The MTN and a number of follow up studies at the ECB and elsewhere in the Eurosystem have also explored the role of the "financial accelerator" in influencing investment (Bernanke, Gertler and Gilchrist (1999)). Broadly these studies tend to find clear evidence that financial factors tend to amplify changes triggered by changes in policy rates. The MTN evidence suggests that firm size typically does not govern the importance of these effects, but there are many predictable differences as to which types of firms respond more or less strongly to changes in interest rates.

There has been less research to date on the role of non-bank financing (and more precisely disturbances to this type of financing) in affecting spending. But, there is a great deal of indirect evidence suggesting that these disturbances could be important. For instance, there is a large literature that studies the predictive power of yield spreads for many macroeconomic variables. Moneta (2005) shows that in the euro area the spread between the ten-year government bond rate and the three month interbank rate is a good predictor of recessions. Importantly, his regressions show that this spread has out of sample forecasting ability, that the spread adds information over and above the information past data on recessions, and that the spread is a more informative forecasting variable than GDP, stock prices and a composite index of leading indicators. This could be accounted for in our framework assuming that $\rho$ should be a long-term interest rate and by associating $\mathrm{z}$ with the term premia.

Christiano, Motto and Rostagno (2005) estimate a small dynamic, stochastic general equilibrium model of the euro area economy that allows for 14 different disturbances. They find that when they suppress financial shocks the model predicts that output volatility would drop substantially (by more than half using their baseline estimates). ${ }^{25}$ Thus they conclude that further modeling of the financial system is critically important for understanding euro area business cycle dynamics.

In the current version of their model, shocks to the net worth of entrepreneurs are the critical financial disturbances. This could captured in (9) by posting that household net worth belongs in $\varepsilon$ or that the residual, z, might be related to net worth. The conjecture that these shocks could be important is also consistent with the findings by Adalid and Detken (2006) that loose money, associated with excessive growth in monetary aggregates, is related to asset price increases and that these increases lead to spending increases (and ultimately recessions).

Thus, a third general proposition about (10) is that there are many routes by which a change in the policy rate might be amplified or dampened due to financial factors. The ECB's monitoring and cross-checking seeks to identify these cases.

Such considerations lead to our fifth question to Issing: how best to characterize the various channels of the monetary transmission mechanism in a theory of monetary policy? Specifically, what monetary and financial shocks are likely to be most relevant? What remain as the least certain features of the transmission mechanism?

\footnotetext{
${ }^{25}$ Dynan, Elmendorf and Sichel (2006) assemble a variety of evidence that suggests that changes in the structure of financial markets have contributed to the decline in volatility of real activity in the United States.
} 
One last issue concerns the role of monetary aggregates. Patinkin $(1965,1968)$ and Humphrey (1997) convincingly show that Wicksell was a main upholder of the quantity theory of money. For example, in Wicksell's cumulative process monetary expansion (contraction) is crucial to accommodate the increase (decline) in prices occurring when the loan rate is below (above) the natural rate. In his Lectures on Political Economy he devotes 50 pages refuting the critics of the classical quantity theory of money. Wicksell (like Fisher) uses the quantity theory to argue that monetary policy can only bear responsibility for the determination of the value of some nominal variable (e.g. the price level). Nevertheless, in our simplified account of the Wicksellian loan rate and our discussion on the implications for the conduct of monetary policy, the explicit role of monetary aggregates has been very limited.

Others have argued for a more central role for monetary aggregates. For example Christiano and Rostagno (2001) argue that monitoring money allows for improvements on the outcomes implied by a Taylor rule, while Nelson (2003) (following a tradition that prominently includes Brunner and Meltzer) states that monetary aggregates may serve as proxy for the substitution effects of monetary policy in an environment where the multiplicity of financial assets matters.

This leads us to our last question to Issing: Is our reading of Wicksell in error? If so, is there a modification of the model in section 3 (or a completely different model) that would make the role of money explicit? Put differently, can we move past the quantity theory to use monetary aggregates more productively in the policy process? 


\section{Conclusion.}

In this paper, we review Otmar Issing's career as the ECB's inaugural chief economist. We began by documenting many notable successes including: 1) the seamless transition to the single monetary policy; 2) the maintenance of price stability over the medium term; 3) low and stable inflation expectations; 4) reduced volatility of key economic variables.

We argue that the standard New Keynesian model, which is widely used in the theory of monetary policy, is able to account for many features that characterize Otmar Issing's approach to the conduct of monetary policy. In particular, it seems to account for Issing's three guiding principles for the successful conduct of monetary policy, namely: 1) Institutions matter. Theoretical reasoning and historical experience show that price stability and central banking independence are the two defining features of sound institutional arrangements. 2) Credibility is fundamental. It is necessary to ensure price stability in a way that is compatible with an overall environment of macroeconomic stability. 3) Temptation must be resisted. In particular, never take credibility for granted, be constantly vigilant and beware of the lasting costs of policy mistakes.

Thirty years ago, Charles Goodhart (1981, page 116) formulated is famous law "that any observed statistical regularity will tend to collapse once pressure is put upon it for control purposes." Issing examined Goodhart's law (in Issing, 1997) and interpreted it as a particular case of the Lucas (1976) critique. Goodhart's law was inspired by the historical example of change and instability of monetary policy in the UK. Thus, Issing decided, inspired by the experience of the Bundesbank, to spin the Lucas critique in the opposite direction. Our favorite formulation of Issing's law ${ }^{26}$ is: "a policy (...) geared to steadiness and medium-term objectives reinforces ... stability ... and hence the foundation of the policy itself." Goodhart's law stresses a vicious circle of instability generating instability. Issing's law, instead, stresses the virtuous circle of stability begetting stability. Thus one of our major conclusions is that the success of the ECB illustrates the practical relevance of Issing's law.

Our second major conclusion is that the link between theory and the practice of monetary policy, at the ECB, under Issing, is the least clear concerning the role of monetary and financial analysis. Our assessment is that this mostly reflects the limited attention that financial factors have received in the theoretical models. We proposed one extension that moves towards filling this gap. While we find the extended model helpful for organizing many observations about practice, we recognize that the lack of foundations to our model is a serious short-coming. We hope that by calling attention to this disconnect between the theory and practice we can trigger more research to close this gap.

Finally, we see the comparison of the theory and practice as raising many questions. We hope, as a parting gift, Issing, in due course, will share his thoughts on these specific questions.

\footnotetext{
${ }^{26}$ In Issing (1997) the reference is clearly to the monetary targeting strategy of the Bundesbank. We have omitted these references in order to highlight the general relevance of Issing's law.
} 
First, given the fact the monetary, economic and political trends are co-determined and co-evolutionary what is the ground for optimism about the future of the European Union? How will political forces affect the operation of the European Central Bank and the Eurosystem?

Second, as a practical matter, what are the most likely threats to the credibility of the European Central Bank? Which temptations are hardest to resist, what mistakes are easiest to make? How important is communication with the European people as prevention against such possibilities?

Third, is time now ripe to consider again the costs and benefits of stabilizing the path for the level of prices (rather than the inflation rate)? Why not price level stability?

Fourth, what are the most important considerations determining the length of the relevant time horizon? How can such considerations be most effectively communicated? Does the unwillingness to commit to a fixed time horizon create temptation that can undermine credibility?

Fifth, how best to characterize the various channels of the monetary transmission mechanism in a theory of monetary policy? Specifically, what monetary and financial shocks are likely to be most relevant? What remain as the least certain features of the transmission mechanism?

Sixth, is our reading of Wicksell is in error? If so, is there a modification of the model in section 3 (or a completely different model) that would make the role of money explicit? Put differently, can we move past the quantity theory to use monetary aggregates more productively in the policy process?

Issing's awareness of the key importance of uncertainty, imperfect knowledge and communication has been, in our view, crucial to his success. As in the concluding quote from Machiavelli, Issing benefited from good fortune:

"(...) anybody wise enough to understand the times and the types of affairs and to adapt himself to them would have always good fortune (...) and it would come to be true that the wise man would rule the stars and the Fates."

Niccolò Machiavelli, January 1513, letter to Piero Soderini in Ragusa, in Allan Gilbert, The Letters of Machiavelli, University of Chicago Press, 1988. 
References

Adalid, A. and C. Detken, 2006, Asset Price Booms and Excess Liquidity, mimeo, ECB.

Alesina, A. and L. Summers, 1993, Central Bank Independence and Macroeconomic Performance: Some Comparative Evidence, Journal of Money, Credit and Banking, 25: 151-62.

Alvarez, L. et al., 2005, Sticky Prices in the Euro Area: a Summary of New Micro Evidence, ECB Working Paper 563, December.

Angeloni, I. et al., 2004, Inflation Persistence in the Euro Area: Preliminary Summary of Findings, available at http://www.ecb.int/events/pdf/conferences/inflationpersistence/IPN interim report d ecb.pdf

Ball, L., N.G. Mankiw and R. Reis, 2003, Monetary Policy for Inattentive Economies, NBER Working Paper 9491, February.

Benigno, P. and M. Woodford, 2004, Inflation Stabilization and Welfare: the Case of a Distorted Steady State, NBER Working Paper, 10838, October.

Bernanke, B., 2000, Japanese Monetary Policy: A Case of Self-Induced Paralysis? in R. Mikitani and A. S. Posen, eds., Japan's Financial Crisis and Its Parallels to U.S. Experience, Washington: Institute for International Economics..

Bernanke, B. and A. Blinder, 1988, Credit, Money and Aggregate Demand, American Economic Review Papers and Proceedings 78: 435-38.

Bernanke, B., M. Gertler and S. Gilchrist, 1999, The Financial Accelerator in a Quantitative Business Cycle Framework, in J. Taylor and M. Woodford (eds.) Handbook of Macroeconomics, Amsterdam: North-Holland.

Blanchard, O., 1990, Why Does Money Affect Output? A Survey, in B. Friedman and F. Hahn (eds.), Handbook of Monetary Economics, Amsterdam: North-Holland.

Blanchard, O. and J. Gali, 2005, Real Wage Rigidities and the New Keynesian Model, NBER Working Paper 11806, November.

Blinder, A., 1999, Central Banking in Theory and Practice, MIT Press.

Brainard, W., 1967, Uncertainty and the Effectiveness of Policy, American Economic Review, 57: 411-425.

Brunner, K. and A. Meltzer, 1972, Money, Debt and Economic Activity, Journal of Political Economy, 80: 951-77.

Brunner, K. and A. Meltzer, 1993, Money and the Economy: Issues in Monetary Analysis, The Raffaelle Matioli Lectures, Cambridge: Cambridge University Press. 
Calvo, G., 1983, Staggered prices in a Utility-Maximizing Framework, Journal of Monetary Economics, 12: 983-98.

Castelnuovo, E., S. Nicoletti-Altimari and D. Rodriguez-Paluenzuela, 2003, Definition of Price Stability, Range and Point Inflation Targets: the Anchoring of Long Term Inflation Expectations, in O. Issing (ed) Background studies for the ECB's evaluation of its monetary policy strategy, Frankfurt: European Central Bank.

Cecchetti, S. and L. Li, 2005, Do Capital Adequacy Requirements Matter for Monetary Policy, NBER Working Paper 11830, December.

Cecchetti, S., Flores-Lagunes A, and S. Krause, 2006, Has Monetary Policy Become More Efficient? A Cross-Country Analysis, Economic Journal, forthcoming.

Chiodo, A. and M. Owyang, 2002, A Case Study of a Currency Crisis: The Russian Default of 1998, Federal Reserve Bank of Saint Louis Review, 7-17, November/December.

Christiano, L.J., Eichenbaum E., and C. Evans, 2005, Nominal Rigidities and the Dynamic Effects of a Shock to Monetary Policy. Journal of Political Economy.

Christiano, L.J. and M. Rostagno, 2001, Money Growth Monitoring and the Taylor Rule, NBER Working Paper, 8539.

Christiano, L.J., Motto, R. and M. Rostagno, 2005, Financial Factors in Business Cycles, mimeo, ECB.

Clarida, R., J. Gali and M. Gertler, 1999, The Science of Monetary Policy: A New Keynsian Perspective, Journal of Economic Literature, 37(4), 1661-707.

Clarida, R., J. Gali and M. Gertler, 2001, Optimal Monetary Policy in Open vs. Closed Economies: An Integrated Approach, American Economic Review, 91, 2: 24852.

Cochrane, J. and M. Piazzesi, 2005, Bond Risk Premia, American Economic Review, 95:1: 138-60.

Coulombe, S., 1997, The Intertemporal Nature of Information Conveyed by the Price System in Price Stability, Inflation Targets and Monetary Policy, Proceedings of a Conference held by the Bank of Canada.

Dixit, A. and J. Stiglitz, 1977, Monopolistic Competition and Optimum Product Diversity, American Economic Review, 67, 3: 297-308.

Dugay, P., 1994, Some thoughts on Price Stability vs. Zero Inflation, paper presented at a conference on Central Bank Independence and Accountability, Bocconi. 
Duisenberg, W., 1999, Economic and Monetary Union in Europe: the Challenges Ahead, in New Challenges for Monetary Policy, a Symposium sponsored by the Federal Reserve of Kansas City.

Dynan K., Elmendorf, D. and D. Sichel, 2006, Can Financial Innovation Help to Explain the Reduced Volatility of Economic Activity?, Journal of Monetary Economics (forthcoming).

ECB, 1998, A Stability Oriented Monetary Policy Strategy for the ESCB, ECB Press Release, 13 October, http://www.ecb.int/

ECB, 1999, The Stability-Oriented Monetary Policy of the Eurosystem, Monthly Bulletin, January, 39-50.

ECB, 2003a, The ECB’s Monetary Policy Strategy, Press release, 8 May.

ECB, 2003b, The Outcome of the ECB's Evaluation of Its Monetary Policy Strategy, Monthly Bulleting, June.

ECB, 2004, The Monetary Policy of the ECB, Frankfurt: European Central Bank.

Fabiani, S., 2005, The Pricing Behaviour of Firms in the Euro Area: New Survey Evidence, ECB Working Paper 535, October.

Federal Open Market Committee Meeting Transcripts, September 29, 1998, available at http://www.federalreserve.gov/fomc/transcripts/1998/980929meeting.pdf

Friedman, M., 1970, A Theoretical Framework for Monetary Analysis, Journal of Political Economy, 78: 193-238.

Gaspar, V., 2003, The Conduct of Monetary Policy under Uncertainty, in Monetary policy and Uncertainty: Adapting to a Changing Economy, a Symposium sponsored by the Federal Reserve of Kansas City.

Gaspar, V., G. Pérez Quirós and J. Sicilia, 2001, The ECB monetary policy strategy and the money market, by V. Gaspar, International Journal of Finance and Economics, 6 (4): 325-42

Gaspar, V. and F. Smets, 2000, Price Stability: Some Issues, National Institute Economic Review, 174: 68-79.

Gertler, M. and J. Leahy. 2006, A Phillips Curve with an Ss Foundation, NBER Working Paper 11971.

Golosov, M. and R. Lucas, 2005, Menu Costs and Phillips Curves, NBER Working paper 10187, revised.

Goodfriend, M., 2002, Monetary Policy in the New Neoclassical Synthesis: a Primer, International Finance, 5 (2): 193-212. 
Goodfriend, M., and R. King, 1997, The New Neoclassical Synthesis and the role of Monetary Policy, NBER Macroeconomics Annual, 12, 231-83.

Goodfriend, M., and R. King, 2001, The Case for Price Stability, in A. GarciaHerrero, V. Gaspar, L. Hoogduin, J. Morgan and B. Winkler (eds), Why Price Stability?, Frankfurt: European Central Bank, 53-94.

Goodhart,. C., 1981, Problems with Monetary Management: the UK experience, in A. Courakis (ed.), Inflation, Depression and Economic Policy in the West, London: Mansell.

Humphrey, T., 1997, Fisher and Wicksell on the Quantity Theory, Federal Reserve of Richmond Economic Quarterly, 83/4, Fall: 71-89.

International Monetary Fund, 2002, Japan: Staff Report for the 2002 Article IV Consultation, Washington, DC.

Issing, O., 1995, The Role of the Central Bank and its Responsibility, in F. Frowen and F. Mc Hugh (eds.), Financial Decision-Making and Moral Responsibility, Basingstoke.

Issing, O., 1997, Monetary targeting in Germany: The stability of monetary policy and of the monetary system, Journal of Monetary Economics, 39, 67-79.

Issing, O., 1999a, The monetary policy of the ECB in a world of uncertainty, contribution to the policy panel at the conference on Monetary policy-making under uncertainty, organised jointly by the European Central Bank and the Center for Financial Studies of the University of Frankfurt, Frankfurt am Main, 3 December.

Issing, O., 1999b, The Eurosystem: Transparent and Accountable or Willem in Euroland, Journal of Common Market Studies, 37, 503-19.

Issing, O., 2000, The ECB's Monetary Policy: Experience After the First Year, Journal of Policy Modeling, 22 (3): 325-43.

Issing, O., 2001a, The single monetary policy of the European Central Bank: one size fits all, International Finance, 4: 441-62.

Issing, O., 2001b, Why Price Stability? In A. Garcia-Herrero et al. (eds), Why Price Stability?, First ECB Central Banking Conference.

Issing, O., 2001c, The euro - the experience of the past 2 years, Journal of Asian Economics, 12: 1-20.

Issing, O., 2002, Monetary Policy in a Changing Economic Environment, in Rethinking Stabilization Policy a Symposium sponsored by the Federal Reserve of Kansas City. 
Issing, O., 2003a, Monetary and Financial Stability: Is there a Trade-off?, Remarks at Conference on Monetary Stability, Financial Stability and theBusiness Cycle, Bank for International Settlements, Basle, March 28-29, 2003.

Issing, O., 2003b, Introductory statement at the ECB Workshop on Asset prices and monetary policy, European Central Bank, Frankfurt, December 11-12, 2003.

Issing, O., 2004, Inflation persistence in the euro area, contribution to the ECB conference 'Inflation persistence in the euro area'; Frankfurt am Main, 10 December 2004.

Issing, O., 2005, The ECB and the euro - the first 6 years: A view from the ECB, Journal of Policy Modeling, 27: 405-20.

Issing, O., V. Gaspar, I. Angeloni and O. Tristani, 2001, Monetary Policy in the Euro Area: Strategy and Decision-Making at the European Central Bank, Cambridge, Cambridge University Press.

Issing, O. et al., 2003, eds., Background studies for the ECB's evaluation of its monetary policy strategy, Frankfurt: European Central Bank.

Issing, O., V. Gaspar, D. Vestin and O. Tristani, 2005, Imperfect Knowledge and Monetary Policy, Cambridge: Cambridge University Press.

Klenow, P. and O. Kryvtsov, 2005, State-Dependent or Time-Dependent Pricing: Does it Matter for Recent US Inflation, NBER Working Paper 11043.

Kohn, D., 2006, Monetary policy and asset prices, at Monetary Policy: A Journey from Theory to Practice, a European Central Bank Colloquium held in honor of Otmar Issing, Frankfurt, Germany.

Kydland, F. and E. Prescott, 1977, Rules Rather than Discretion: the Inconsistency of Optimal Plans, Journal of Political Economy, 85: 473-92.

Lucas, R., 1976, Econometric Policy Evaluation: a Critique, Carnegie-Rochester Conference Series on Public Policy, 29: 173-204.

Lucas, R. and N. Stokey, 1983, Optimal Fiscal and Monetary Policy in an Economy without Capital, Journal of Monetary Economics, 12: 55-93.

Masuch, K., 2005, Price Stability and Macroeconomic Volatility in the euro area - the Positive Supply-Side Effects of Credible and Predictable Monetary Policy, in M. Heise and V. Wieland (eds.), Capital Markets in the Long Term: Demography, Economic Developments and Funded Pension Systems, Center for Financial Studies.

Moneta, F., 2005, Does the Yield Spread Predict Recessions in the Euro Area?, International Finance, 8:2, 263-301.

Nelson, E., 2003, The future of monetary aggregates in monetary policy analysis, Journal of Monetary Economics, 50: 1029-59. 
Obstfeld, M., 1998, EMU: Ready, or Not?, Princeton Essays in International Economics, 209, also available as http://elsa.berkeley.edu/ obstfeld/graham.pdf

Patinkin, D., 1965, Money, Interest and Prices, $2^{\text {nd }}$ Edition, New York: Harper \& Row.

Patinkin, D., 1968, Wicksell's Cumulative Process in Theory and Practice, Banca Nationale del Lavoro Quarterly Review, 85, June: 120-31.

Ramsey, F., 1927, A Contribution to the Theory of Taxation, Economic Journal, 37: 47-61.

Rogoff, K., 1985, The optimal degree of commitment to an intermediate monetary target, Quarterly Journal of Economics, 100, 1169-90.

Shiller, R., 1997, Public Resistance to Indexation: a Puzzle, Brookings Papers on Economic Activity, 1, 159-211.

Simon, H., 1956, Dynamic Programming under Uncertainty with a Quadratic Criterion, Econometrica, 24: 74-81.

Smets, F. and R. Wouters, 2003, An Estimated Stochastic General Equilibrium Model for the Euro Area, Journal of the European Economic Association, 1, 5: 1123-75.

Steinsson, J., 2003, Optimal Monetary Policy in an Economy with Inflation Persistence, Journal of Monetary Economics, 50, 7.

Svensson, L. and M. Woodford, 2003, Indicator Variables for Optimal Policy, Journal of Monetary Economics, 50: 621-50.

Svensson, L. and M. Woodford, 2005, Implementing Optimal Policy Through Inflation-Forecast Targeting, in B. Bernanke and M. Woodford (eds.), The Inflation Targeting Debate, Chicago: University of Chicago Press.

Theil, H., 1954, Econometric Models and Welfare Maximization, Weltwirtschaftigsches Archiv, 72: 60-83.

Theil, H., 1957, A Note on Certainty Equivalence in Dynamic Planning, Econometrica, 25: 346-49.

Tinbergen, J., 1952, On the Theory of Economic Policy, Amsterdam: North-Holland.

Tobin, J., 1969, A General equilibrium Approach to Monetary Theory, Journal of Money, Credit and Banking, 1, 15-29.

Vestin, D., 2006, Price Level Targeting vs Inflation Targeting in a Forward-Looking Model, Journal of Monetary Economics, forthcoming. 
Walsh, C., 1995, Optimal Contracts for Central Bankers, American Economic Review, 85, 1: 150-67.

Walsh, C., 1998, Monetary Theory and Policy, Cambridge, MIT Press.

Wicksell, K., 1935, Lectures on Political Economy: volume two - Money, London: Routledge \& Keegan Paul.

Woodford, M., 2003, Interest \& Prices: Foundations of a Theory of Monetary Policy, Princeton: Princeton University Press. 
Chart 1: Inflation in the euro area.

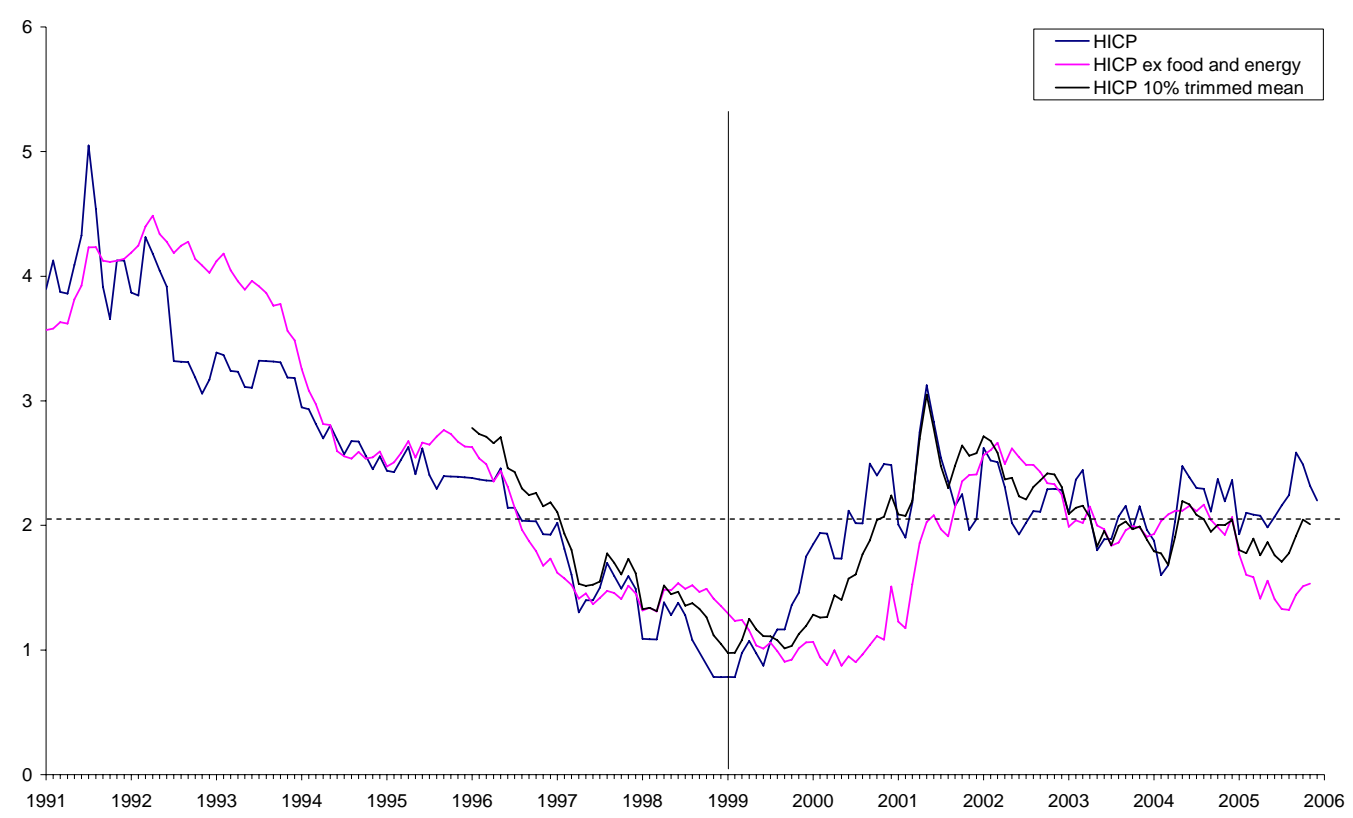


Chart 2: Long run inflation expectations in the euro area.

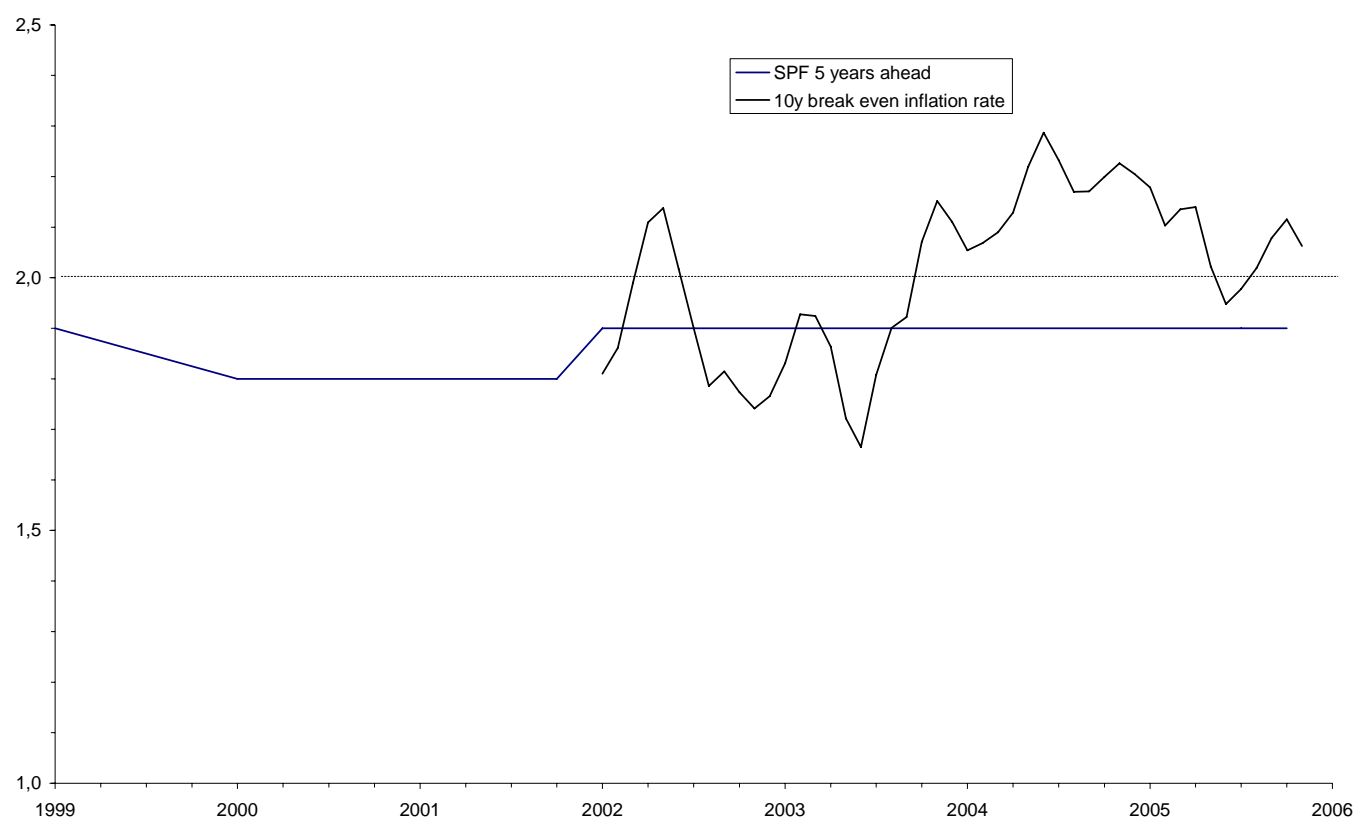


Chart 3: Money market and policy interest rates

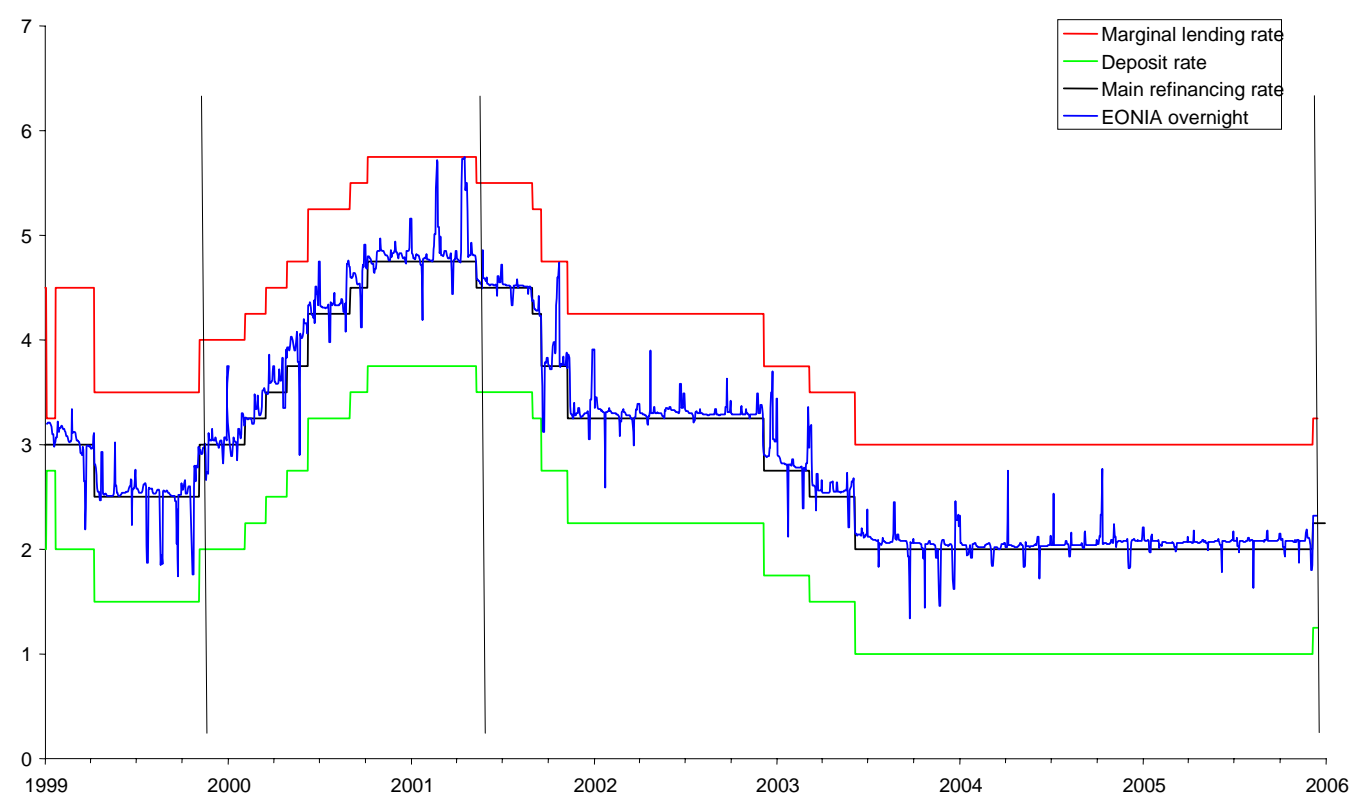


Chart 4: The ECB's Stylized Depiction of the Monetary Transmission Mechanism

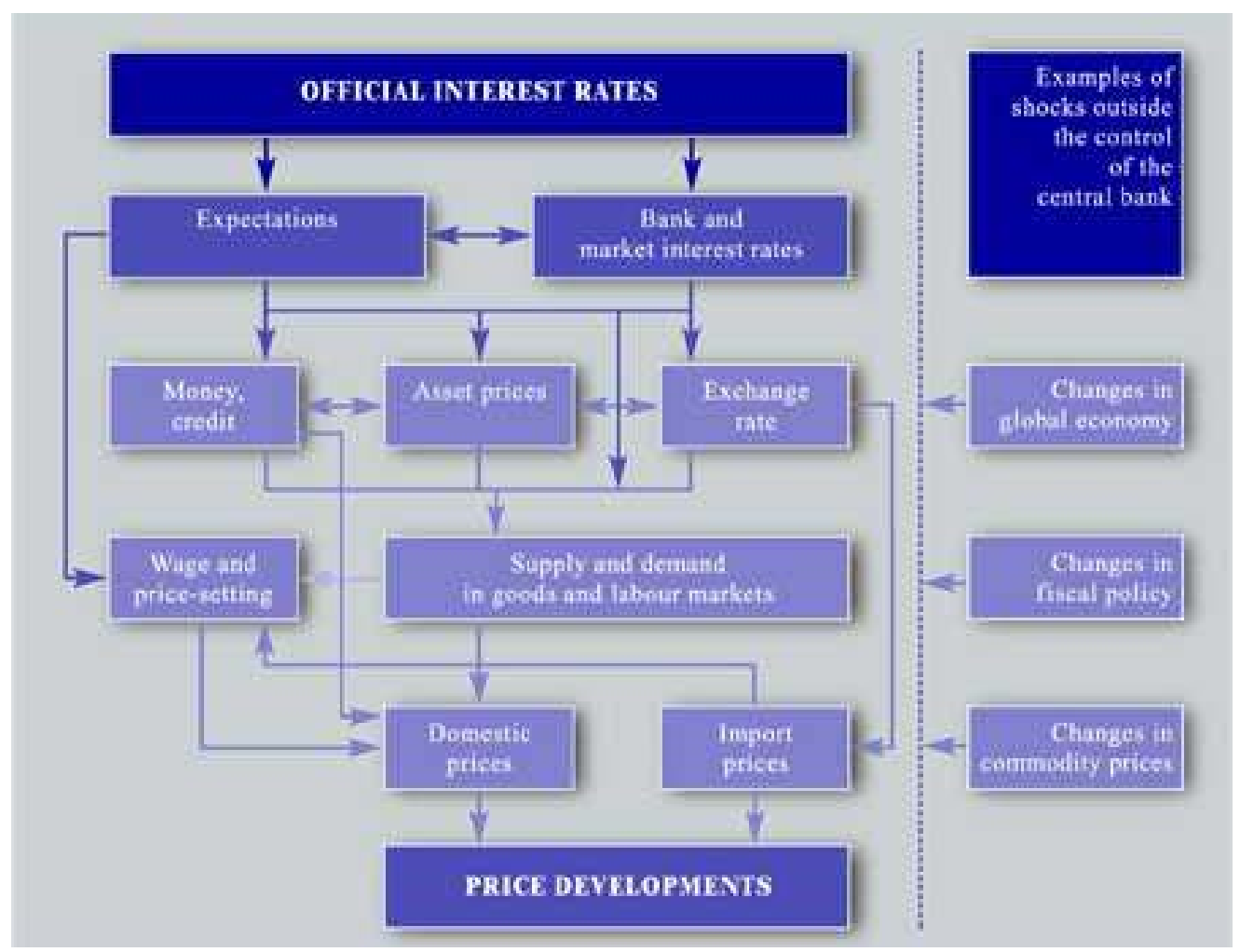

